\title{
BMJ Open Characteristics and healthcare utilisation patterns of high-cost beneficiaries in the Netherlands: a cross- sectional claims database study
}

\author{
Joost Johan Godert Wammes, ${ }^{1}$ Marit Tanke, ${ }^{1}$ Wilma Jonkers, ${ }^{2}$ Gert P Westert, ${ }^{3}$ \\ Philip Van der Wees, ${ }^{1}$ Patrick PT Jeurissen ${ }^{1}$
}

To cite: Wammes JJG, Tanke M, Jonkers W, et al. Characteristics and healthcare utilisation patterns of high-cost beneficiaries in the Netherlands: a cross-sectional claims database study. BMJ Open 2017;7:e017775. doi:10.1136/ bmjopen-2017-017775

\section{- Prepublication history and} additional material for this paper are available online. To view these files, please visit the journal online (http://dx.doi. org/10.1136/bmjopen-2017017775).

Received 22 May 2017 Revised 29 August 2017 Accepted 25 September 2017

\section{CrossMark}

${ }^{1}$ Scientific Institute for Quality of Healthcare, Celsus Academy for Sustainable Healthcare, Radboud university medical center, Nijmegen, The Netherlands

${ }^{2}$ Kenniscentrum - Research Consultancy, Zilveren Kruis, Zwolle, The Netherlands ${ }^{3}$ Scientific Institute for Quality of Healthcare, Radboud university medical center, Nijmegen, The Netherlands

\section{Correspondence to} Joost Johan Godert Wammes; Joost.Wammes@radboudumc. nl, jjgwammes@gmail.com

\section{ABSTRACT}

Objective To determine medical needs, demographic characteristics and healthcare utilisation patterns of the top $1 \%$ and top $2 \%-5 \%$ high-cost beneficiaries in the Netherlands.

Design Cross-sectional study using 1 year claims data. We broke down high-cost beneficiaries by demographics, the most cost-incurring condition per beneficiary and expensive treatment use.

Setting Dutch curative health system, a health system with universal coverage.

Participants 4.5 million beneficiaries of one health insurer.

Measures Annual total costs through hospital, intensive care unit use, expensive drugs, other pharmaceuticals, mental care and others; demographics; most costincurring and secondary conditions; inpatient stay; number of morbidities; costs per ICD10-chapter (International Statistical Classification of Diseases, 10th revision); and expensive treatment use (including dialysis, transplant surgery, expensive drugs, intensive care unit and diagnosis-related groups $>€ 30000$ ).

Results The top $1 \%$ and top $2 \%-5 \%$ beneficiaries accounted for $23 \%$ and $26 \%$ of total expenditures, respectively. Among top $1 \%$ beneficiaries, hospital care represented $76 \%$ of spending, of which, respectively, $9.0 \%$ and $9.1 \%$ were spent on expensive drugs and ICU care. We found that $54 \%$ of top $1 \%$ beneficiaries were aged 65 years or younger and that average costs sharply decreased with higher age within the top $1 \%$ group. Expensive treatments contributed to high costs in onethird of top $1 \%$ beneficiaries and in less than $10 \%$ of top $2 \%-5 \%$ beneficiaries. The average number of conditions was 5.5 and 4.0 for top $1 \%$ and top $2 \%-5 \%$ beneficiaries, respectively. $53 \%$ of top $1 \%$ beneficiaries were treated for circulatory disorders but for only $22 \%$ of top $1 \%$ beneficiaries this was their most cost-incurring condition.

Conclusions Expensive treatments, most costincurring condition and age proved to be informative variables for studying this heterogeneous population. Expensive treatments play a substantial role in highcosts beneficiaries. Interventions need to be aimed at beneficiaries of all ages; a sole focus on the elderly would leave many high-cost beneficiaries unaddressed. Tailored interventions are needed to meet the needs of high-cost beneficiaries and to avoid waste of scarce resources.
Strengths and limitations of this study

- This study presents an in-depth analysis of the medical needs, demographics and healthcare utilisation of high-cost beneficiaries in the Netherlands.

- We characterised high-cost beneficiaries and spending patterns using several variables, including expensive treatment use (eg, dialysis, expensive drugs and intensive care unit), most cost-incurring condition and age.

- Analyses were limited to one large insurer, but its beneficiaries are representative for the Netherlands.

\section{INTRODUCTION}

It is known that healthcare costs are concentrated among small numbers of 'high-cost' beneficiaries. These high-cost beneficiaries are the sickest and most complex populations. Although they receive substantial care from multiple sources, critical healthcare needs are often unmet, and many receive unnecessary and ineffective care. ${ }^{1-4}$ Therefore, highcost beneficiaries are a useful group on which to focus efforts of quality improvement and cost containment.

For effective quality improvement and cost reduction, it is necessary to acquire an in-depth understanding of the characteristics, healthcare use and other factors that drive the costs of these groups of high-cost beneficiaries. ${ }^{56}$ Current literature suggests that a high prevalence of multiple (chronic) conditions may explain high-cost beneficiaries' excessive care use. ${ }^{78}$ This presence of multimorbidity among high-cost beneficiaries makes them difficult to understand: how to characterise patients that suffer from several diseases? Lehnert $e t$ a $t^{\theta}$ found that the number of chronic comorbidities were nearly exponentially related to costs: the higher the number of chronic comorbidities, the higher 


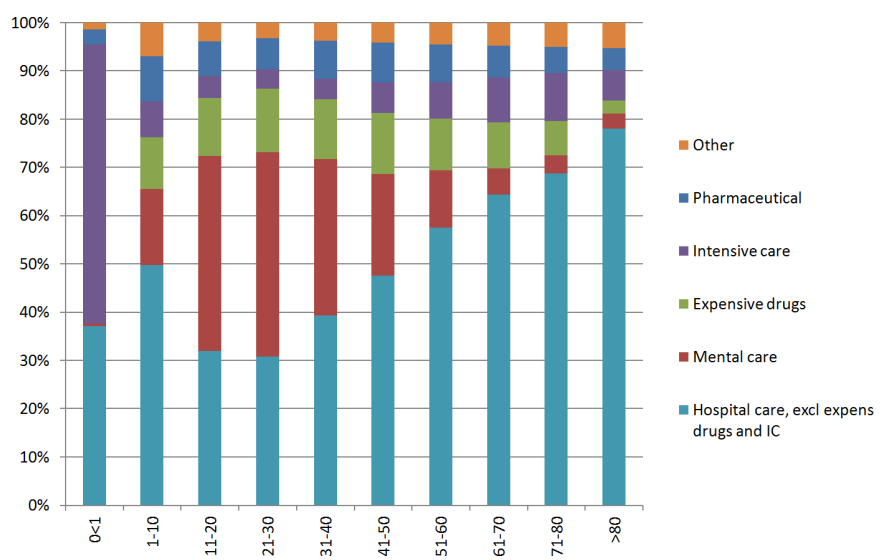

Figure 1 Cost drivers per age group in top 1\% beneficiaries.

the costs of an additional comorbidity. Based on this study, we hypothesised that in high-cost beneficiaries the most cost-incurring condition accounts for a disproportionate share of costs and that secondary conditions account for the remainder of costs.

A major limitation of current literature is that little is known about patterns in care use and characteristics among different age groups. ${ }^{10}$ In addition, until today, no studies have reported the role of expensive treatments (eg, expensive drugs, transplant surgery, intensive care units (ICUs) and dialysis) as drivers of high costs. Further insight in healthcare utilisation patterns is needed to develop interventions and inform policy aimed at highneed, high-cost populations.

The primary aim of this study was to determine medical needs, demographic characteristics and healthcare utilisation patterns of high-cost beneficiaries in the Netherlands. We first determined characteristics and spending and quantified the share of high-cost beneficiaries that use expensive treatments. We then used a beneficiary's most cost-incurring medical condition to examine characteristics and utilisation patterns. In addition, we compared utilisation and conditions across age groups. All analyses were performed for top $1 \%$ and top $2 \%-5 \%$ beneficiaries separately. This distinction is often used in literature $^{11-14}$ and may improve understanding of highcost beneficiaries.

\section{METHODS}

\section{Design and context}

We conducted an cross-sectional study using claims data from 2013 in the Netherlands. In the Netherlands, the Health Insurance Act legally requires health insurers to provide a nationally set benefits package. Nearly universal coverage for curative care is achieved through mandatory purchase of statutory private health insurance. ${ }^{15} 16$ Analyses were done in-house with Zilveren Kruis, a health insurer covering 4.5 million beneficiaries who were primarily living in the central, eastern and western parts of the Netherlands. The basic principle of the Dutch curative health system is that insurers compete for beneficiaries and that they act as prudent buyers of services for their beneficiaries. Health insurers operate nationwide, are obliged to accept all applicants for basic health plans and are not permitted to risk-rate premiums for these basic plans. Every insured person, aged 18 years or older, is required to pay an annual deductible (€350 in 2013), from which some services, such as general practice visits, are excluded. In addition to the basic health plan, more than $80 \%$ of the population buys voluntary insurance. Premiums for voluntary insurance are not regulated, and insurers are allowed to screen applicants. The system provides a wide range of services, including care provided by general practitioners, hospitals and specialists, dental care through age 18 years, prescription drugs, physiotherapy through age 18 years, most mental care, medical aids and devices, maternity care, transportation and others. In our study, we also included private voluntary supplementary insurance that typically covers dental care, some allied healthcare (including physiotherapy, occupational therapy, dietary advice and speech therapy) and complementary medicine (typically homoeopathy, acupuncture, natural medicine, magnetising and osteopathy).

\section{Data}

All insured in 2013 were included in this study. Several beneficiary characteristics were obtained from the insurer's databases, including gender, socioeconomic status based on income estimates per postal code, date of birth and date of death (until 20 February 2015). Date of death was categorised to four quarters in 2013 and any date post-2013. More information about (a predecessor of) this database is provided in Smeets et al. ${ }^{17}$

Total costs per beneficiary were calculated by summing all claims with a starting date in 2013. We defined the beneficiaries with the top $1 \%$ and the top $2 \%-5 \%$ of total costs as two groups of high-cost beneficiaries. The remaining $95 \%$ were categorised as low-cost beneficiaries. All claims were categorised in nine cost groups (health sectors) using a link table provided by the Dutch Healthcare Institute. These sectors included: hospital care (including care used abroad), mental healthcare, primary care, maternal care, allied healthcare, outpatient pharmaceutical prescriptions, medical devices, dental care (most dental care is reimbursed through complementary insurance benefits) and voluntary complementary insurance benefits.

Below, we describe how we operationalised the variables that we included in our analysis, including the treatment costs per diagnosis, the prevalence of conditions and multimorbidity count and the use of specific (expensive) services.

\section{Treatment cost per diagnosis}

We categorised and analysed hospital and mental care costs, according to the International Statistical Classification of Diseases, 10th revision (ICD-10) ${ }^{18}$ Treatment 
costs were categorised to the level of ICD-10 chapters (eg, chapter IX: diseases of the circulatory system) and ICD-10 subchapters (eg, subchapter I60-I69 cerebrovascular diseases).

The great majority of hospital care in the Netherlands is reimbursed through payment products similar to diagnosis-related groups (DRGs, which cover both inpatient and outpatient hospital care) and so-called add-ons for expensive drugs and treatment at the ICU. To compute treatment costs per diagnosis, the DRGs were categorised using a link table provided by the Dutch Health Care Authority. This link table (version 22 December 2014) was developed to categorise hospital claims to specific healthcare needs, following the ICD-10 classification. ${ }^{18}$ For the purpose of our study, we made a few minor corrections to the link table. As we found the ICD subchapter I30-I52 (other circulatory diseases) highly prevalent but not informative, we decided to disaggregate this subchapter. Add-ons were not used for establishing treatment cost per diagnosis but are dealt with separately (see 'use of specific expensive services').

In 2013, the Dutch mental care sector consisted of 'primary' mental care, such as care provided at general practices, by psychologists and psychotherapists, and at 'secondary' or specialised mental care provided in mental care institutions. Only claims from secondary mental healthcare were used for characterisation as these specify information about diagnoses and treatment. These claims were categorised to the ICD-10 (sub) chapter and added to the hospital claims for ICD-10 chapter V: mental and behavioural disorders. Additionally, the number of inpatients days in mental care per beneficiary was calculated (but not used for establishing treatment cost).

\section{Prevalence of conditions and multimorbidity count}

Prevalence of conditions was established using the same categorisation as described above. In addition, we used parameters from the Dutch risk adjustment scheme: pharmaceutical cost groups that indicate chronic use of drugs for different conditions. These pharmaceutical cost groups were categorised to ICD-10 (sub-)chapters and integrated with the former to establish prevalence of conditions. A detailed description of the Dutch risk adjustment scheme is provided in van Veen. ${ }^{19}$ Multimorbidity was operationalised in three ways. First, multimorbidity was calculated by counting the number of prevalent ICD-10 chapters per beneficiary. Second, we counted the number of prevalent ICD-10 subchapters per beneficiary. Third, the number of pharmaceutical cost groups was counted, reflecting the number of chronic multimorbidities.

\section{Use of specific (expensive) services}

We developed dummy variables for specific types of care. Beneficiaries were regarded 'expensive care users' if their claims included a minimum of $€ 10000$ for 'add-ons' for ICU treatment or expensive drugs. We used $€ 10000$ as threshold because in 2013 expensive drugs only qualified for add-on reimbursement when average yearly costs per beneficiary exceeded this value. ICU treatment as reimbursed through add-ons included ICU treatment days, ICU consultations, ICU surcharges for specific services, ICU neonatal and paediatric care and ICU transport services such as interclinical transportation services and mobile intensive care unit. Expensive drugs reimbursed through add-ons included growth hormones, antineoplastic agents, tumour necrosis factor-alpha inhibitors, orphan drugs, haemostatics and other expensive drugs. ${ }^{20}$ The list of drugs and indications that qualify for add-on reimbursement can be found at www.farmatec.nl

A separate dummy variable 'transplant' was developed, for beneficiaries who received a transplant or transplant-related care (both pretransplant and post-transplant). One DRG description that included the word 'transplant' was sufficient for a person to qualify as transplant beneficiary. Similarly, the variable 'dialysis' was created for all beneficiaries receiving dialysis for renal failure (both peritoneal and haemodialysis). In addition, all DRGs with an average price $>€ 30000$ were identified and together included as separate binary variable. This price was chosen as all top $1 \%$ beneficiaries incurred $€ 30000$ or more. Furthermore, two dummy variables for mental health use were computed, the first on mental care use $(>€ 0$ mental care costs) and the second on inpatient stays ( $>0$ days). The total number of inpatient hospital days per beneficiary was estimated using national averages of hospital days per DRG. ${ }^{21}$ Finally, we used claims data to derive the number of different hospitals, university medical centres and hospital specialisms that beneficiaries were treated at, as well as the number of ambulance transportations, and emergency department visits. For full details concerning the variable computation, please contact the corresponding author.

\section{Analyses}

We explored the composition of expenditures across health sectors for both top $1 \%$ and top $2 \%-5 \%$ beneficiaries. Demographics, medical characteristics and (expensive) healthcare use were analysed using descriptive statistics.

\section{Most cost-incurring and secondary conditions}

For each high-cost beneficiary, we identified the most cost-incurring ICD-10 (sub)chapter. For both top 1\% and top $2 \%-5 \%$ beneficiaries, we first determined the prevalence of each ICD-10 subchapter. Second, for both high-cost groups we summed treatment cost per ICD-10 subchapter and divided this with the sum of total costs. Third, for each ICD-10 subchpater, we calculated how frequently it was the most cost-incurring condition for the beneficiaries in these groups. Fourth, we divided the percentage of beneficiaries with a ICD-10 subchapter as the most cost-incurring condition by the overall prevalence of the ICD-10 subchapter. This metric was used to distinguish between ICD-10 subchapters that were mainly found as most cost-incurring conditions compared with 
ICD-10 subchapters that were mainly found as secondary conditions. Fifth, for each beneficiary, we divided the treatment cost for the most cost-incurring condition by total costs. This figure was averaged for each ICD-10 subchapter and determines the contribution of these conditions to total costs within the subpopulation.

\section{Healthcare use according to most cost-incurring ICD-10 chapter} and across age groups

To identify patterns in (expensive) healthcare use, we developed cross-tables with costs per ICD-10 chapter, (expensive) healthcare use indicators and demographic characteristics as descriptive variables. Beneficiaries were selected by the most cost-incurring ICD-10 chapter to prevent that beneficiaries with multimorbidity would be counted several times.

Finally, we compared utilisation patterns and conditions across age groups. We examined total costs and spending per sector, and we identified the five most cost-incurring ICD-10 chapters per age group.

All analyses were performed using SAS V.9.4, Enterprise Guide 6.1.

\section{RESULTS}

\section{General breakdown of costs}

Average total costs for top 1\%, top 2\%-5\% and bottom $95 \%$ beneficiaries were $€ 56424, € 15780$ and $€ 1345$, respectively, representing 22.8\%, 25.5\% and $51.7 \%$ of total spending (table 1). For top $1 \%$ beneficiaries, hospital care represented $76 \%$ of costs, of which, respectively, $9.0 \%$ and $9.1 \%$ were for expensive drugs and ICU care. $12.7 \%$ and $6.6 \%$ of costs were for mental healthcare and outpatient pharmaceuticals, respectively. For top $2 \%-5 \%$ beneficiaries, hospital care represented $59.7 \%$ of spending, of which $6.0 \%$ and $2.1 \%$ were spent on expensive drugs and ICU care, while $9.8 \%$ and $11.2 \%$ were spent on mental healthcare and outpatient pharmaceuticals.

\section{Demographics and (expensive) healthcare use}

Table 1 presents demographic and medical characteristics of the study population as well as (expensive) healthcare use. Males were over-represented among top $1 \%$ beneficiaries, and females were over-represented among top $2 \%-5 \%$ beneficiaries. Top $1 \%$ and top $2 \%-5 \%$ beneficiaries were much older than low-cost beneficiaries. Furthermore, high-cost beneficiaries were more likely to die: $9.9 \%$ and $6.1 \%$ of top $1 \%$ and top $2 \%-5 \%$ beneficiaries died. However, $63.7 \%$ of beneficiaries in our study who died in 2013 or later did not incur high costs in 2013. The average number of morbidities based on ICD-10 subchapters for top $1 \%$, top $2 \%-5 \%$ and bottom $95 \%$ beneficiaries was 5.5, 4.0 and 0.8 , respectively.

Table 1 also shows that top $1 \%$ and top 2\%-5\% beneficiaries scored higher than low-cost users for each specific service, and top $1 \%$ beneficiaries scored higher than top $2 \%-5 \%$ beneficiaries. Both top $1 \%$ and top $2 \%-5 \%$ beneficiaries used on average one type of drugs (pharmaceutical cost groups) continuously. A percentage of 24.8 of top $1 \%$ and $5.8 \%$ of top $2 \%-5 \%$ beneficiaries incurred more than $€ 10000$ on expensive drugs and ICU. Furthermore, $6.1 \%$ of top $1 \%$ beneficiaries underwent dialysis and $3.7 \%$ received transplant care. Top $1 \%$ and top $2 \%-5 \%$ beneficiaries were treated in on average 1.9 and 1.6 hospitals, and used on average 22 and 7 inpatient days, respectively. Finally, 13\% and $3.3 \%$ of top $1 \%$ and top $2 \%-5 \%$ beneficiaries were admitted to mental care institutions, respectively.

\section{Utilisation according to ICD-10 subchapters and most cost- incurring and secondary conditions,}

Online appendix 1 presents five parameters for both high-cost populations. Among those in the top $1 \%$, a high prevalence of several cardiovascular diseases, chronic obstructive pulmonary disease, diabetes mellitus and depression were found. In addition, the total treatment costs for renal insufficiency (including dialysis) were much higher than for any other ICD-10 subchapter and accounted for $6.8 \%$ of total costs among top $1 \%$ beneficiaries. We use table 2 , with a selection of 10 ICD-10 subchapters in top $1 \%$ beneficiaries, to illustrate the other parameters for top $1 \%$ beneficiaries. Renal insufficiency, certain cancers and several cardiovascular diseases were frequently found as the most cost-incurring condition among top $1 \%$ beneficiaries. Furthermore, for beneficiaries that were treated for cancer, the cancer itself was in most cases the most cost-incurring condition (eg, $74.3 \%$ of beneficiaries with leukaemia). In contrast, circulatory disorders were mainly found as secondary condition: for example, in less than $30 \%$ of patients with ischaemic heart disease or heart failure, this was their most cost-incurring condition. Finally, we determined the contribution of ICD-10 subchapters towards total costs per beneficiary. The most cost-incurring condition accounted for $40 \%-70 \%$ of total costs per beneficiary, depending on the ICD-10 subchapter.

\section{Utilisation according to most cost-incurring ICD-10 chapter}

Table 3 and online appendix 2 show cross-tables for spending, demographics and indicators for (expensive) healthcare use. In these analyses, beneficiaries were selected by most cost-incurring ICD-10 chapter to avoid multimorbid beneficiaries being analysed on multiple rows. Among top $1 \%$ beneficiaries, three ICD-10 chapters were frequently found as most cost-incurring ICD-10 chapter: mental or behavioural disorders, neoplasms and diseases of the circulatory system. These groups had quite different characteristics and utilisation. Beneficiaries with mental or behavioural disorders were relatively young, had a low number of morbidities and low mortality. Beneficiaries with neoplasms were the largest subgroup with high mortality. Beneficiaries with diseases of circulatory system were oldest (on average 69 years old) and predominantly men. Expensive drugs were heavily concentrated among beneficiaries with neoplasms. ICU costs were 
Table 1 General characteristics and indicators for healthcare use for three distinct cost groups

\begin{tabular}{|c|c|c|c|}
\hline General characteristics & Top 1\% & Top $2 \%-5 \%$ & Bottom 95\% \\
\hline Number of beneficiaries & 45207 & 180826 & 4294611 \\
\hline Average total costs (SD) & $\begin{array}{l}€ 56424 \\
(€ 40830)\end{array}$ & $\begin{array}{l}€ 15780 \\
(€ 5208)\end{array}$ & $\begin{array}{l}€ 1345 \\
(€ 1773)\end{array}$ \\
\hline Share of total costs (\%) & 22.8 & 25.5 & 51.7 \\
\hline Private spending ${ }^{\star}(\mathrm{SD})$ & $€ 330(€ 172)$ & $€ 335$ (€165) & $€ 159(€ 181)$ \\
\hline Female & 47.7 & 55.2 & 50.4 \\
\hline Mean age (SD) & $58.5(21.6)$ & $58.0(21.8)$ & $39.2(23.3)$ \\
\hline Median age (years) & 64 & 62 & 39 \\
\hline
\end{tabular}

Percentage dying in or after study period (\%)

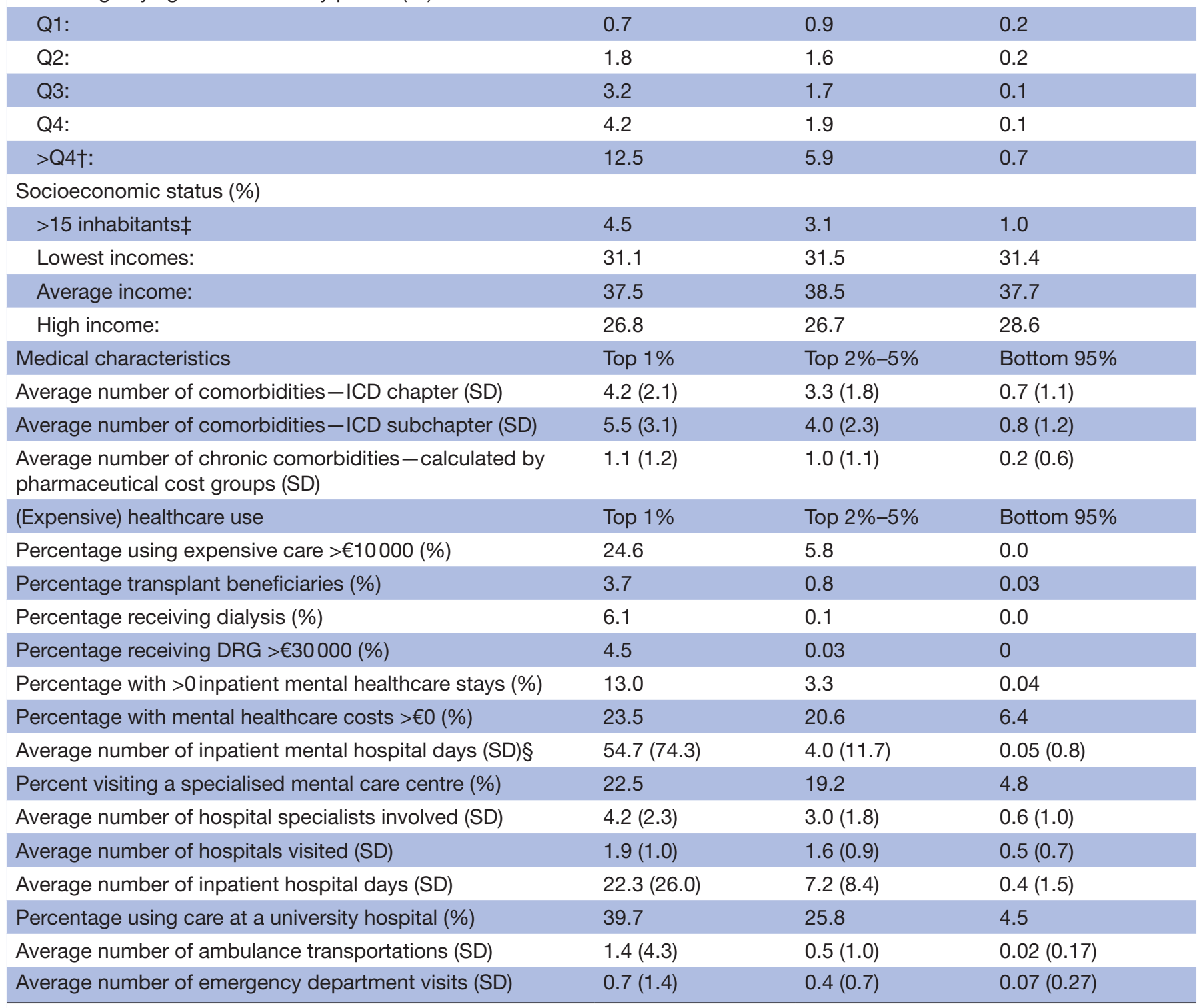

${ }^{*}$ Consisting of the compulsory deductible of $€ 350$.

†Dates of death were recorded until the 20 February 2015.

$\ddagger$ Most of whom are institutionalised.

$\S$ For those with mental healthcare costs $>€ 0$.

DRG, diagnosis-related groups; ICD, International Statistical Classification of Diseases. 
Table 2 Ten conditions with highest total costs among top $1 \%$ beneficiaries

\begin{tabular}{|c|c|c|c|c|c|}
\hline & Prevalence $(\%)^{*}$ & $\begin{array}{l}\% \text { of total } \\
\text { costs } †\end{array}$ & $\begin{array}{l}\% \text { as most } \\
\text { cost- } \\
\text { incurring } \\
\text { condition } ¥\end{array}$ & $\begin{array}{l}\% \text { most cost- } \\
\text { incurring/ } \\
\text { prevalence }\end{array}$ & $\begin{array}{l}\% \text { of costs by most } \\
\text { cost-incurring } \\
\text { condition }\rceil\end{array}$ \\
\hline C81-C96 Leukaemia & 5.6 & 3.0 & 4.1 & 74.3 & 41.4 \\
\hline $\begin{array}{l}\text { C15-C26 Malignant } \\
\text { neoplasms of digestive } \\
\text { organs }\end{array}$ & 7.5 & 2.4 & 5.4 & 71.2 & 47.9 \\
\hline $\begin{array}{l}\text { I60-I69 Cerebrovascular } \\
\text { diseases }\end{array}$ & 7.9 & 2.1 & 4.2 & 53.1 & 52.7 \\
\hline $\begin{array}{l}\text { I70-I79 Diseases of arteries, } \\
\text { arterioles and capillaries }\end{array}$ & 9.6 & 2.0 & 4.1 & 42.7 & 47.3 \\
\hline $\begin{array}{l}\text { 144-149 Atrial fibrillation, } \\
\text { rhythm and conduction } \\
\text { disorders }\end{array}$ & 11.8 & 1.6 & 2.9 & 24.3 & 58.5 \\
\hline $\begin{array}{l}\text { I20-I25 Ischaemic heart } \\
\text { diseases }\end{array}$ & 12.7 & 1.6 & 3.7 & 29.0 & 41.9 \\
\hline 150 Heart failure & 9.3 & 1.5 & 2.6 & 28.4 & 57.1 \\
\hline
\end{tabular}

*Prevalence of each ICD-10 subchapter among top 1\% beneficiaries. For example, $12.2 \%$ of top $1 \%$ beneficiaries were treated for renal failure.

†Sum of total treatment costs per ICD-10 subchapter. For example, treatment of renal failure accounted for $6.8 \%$ of total expenditures of top $1 \%$ beneficiaries.

¥Percentage of top $1 \%$ with this ICD-10 subchapter as most cost-incurring condition. For example, $6.4 \%$ of top $1 \%$ beneficiaries had renal failure as most cost-incurring condition.

§Percentage most cost-incurring condition relative to prevalence: fourth column divided by second column. For example, for $52.4 \%$ of top $1 \%$ beneficiaries who were treated for renal failure, this was also their most cost-incurring condition.

IPercentage of costs accounted for by the most cost-incurring condition. For example, among top 1\% beneficiaries with renal failure as most cost-incurring condition, this disease accounted for on average $66 \%$ of total costs per beneficiary.

distributed more proportionally; a quarter was incurred by beneficiaries with circulatory diseases.

Among top 2\%-5\% beneficiaries, the same three most cost-incurring ICD-10 chapters predominated, although they represented a smaller share of the group. Several other ICD-10 chapters had relatively high costs, including diseases of the digestive system; injury, poisoning and certain other consequences of external causes (femur fracture most prominently); and diseases of the musculoskeletal system and connective tissue. Beneficiaries with neoplasms, diseases of the respiratory system and symptoms, signs and abnormal clinical and laboratory findings most frequently died. Expensive drugs were primarily used by beneficiaries with diseases of the musculoskeletal system (rheumatoid arthritis), neoplasms and diseases of the digestive system.

\section{Healthcare use across age groups}

This Figure 1 and online appendix 3 provide an overview of cost segments per age category among top $1 \%$ and top $2 \%-5 \%$ beneficiaries. With the exception of infants, treatment at the ICU represented a maximum of $10 \%$ of costs per age group. Moreover, treatment at the ICU represented a major cost driver primarily among top $1 \%$ beneficiaries. The proportion of costs spent on expensive drugs was highest (13.4\% of total costs) among top $1 \%$ beneficiaries between 21 and 30 years old. Mental care accounted for a large share of costs among children and young and middle-aged adults. The percentage of cost incurred by outpatient and non-expensive pharmaceuticals was more pronounced among top $2 \%-5 \%$ beneficiaries than among top $1 \%$ beneficiaries.

Table 4 and online appendix 4 present the five ICD-10 chapters with highest total costs per age group for top $1 \%$ and top $2 \%-5 \%$ beneficiaries. As mentioned before, we found that high-cost beneficiaries are generally older than low-cost beneficiaries. However, table 4 shows that within the top $1 \%$ beneficiaries average costs decreased with higher age: average costs ranged from $€ 47000$ on average for top $1 \%$ beneficiaries over 80 years of age to $>€ 80000$ on average for infants. In addition, $54 \%$ of top $1 \%$ and $57 \%$ of top $2 \%-5 \%$ beneficiaries were 65 years of age or younger. 


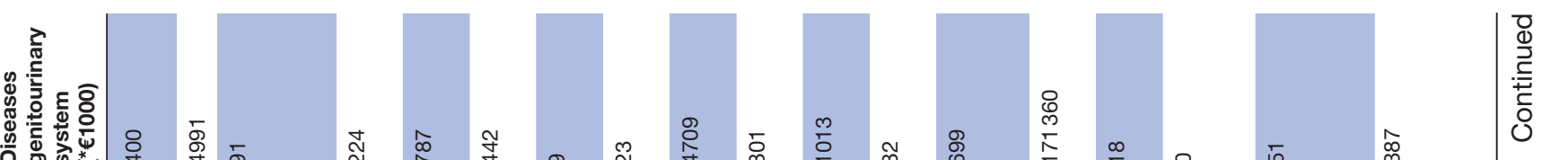

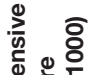

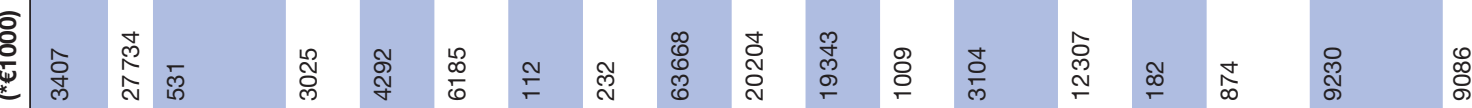

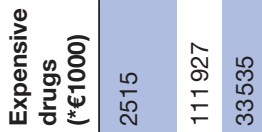
范

\section{ฐ๐ํㅇ}

这焉

in

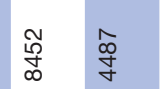

点

\section{志}

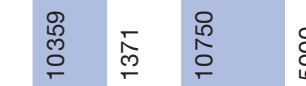

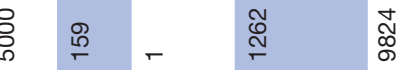

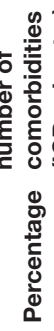

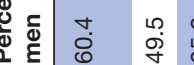

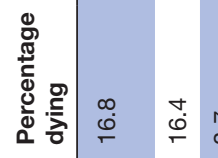

बำ

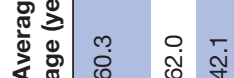

范

范

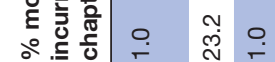

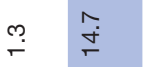

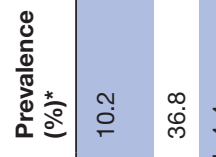

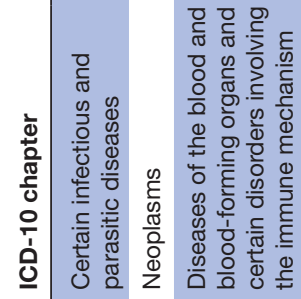

ำ

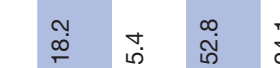
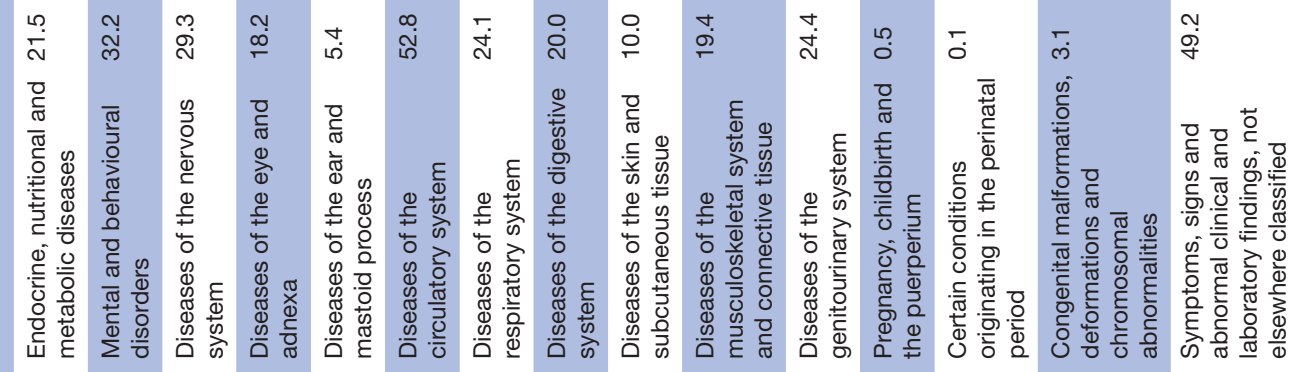


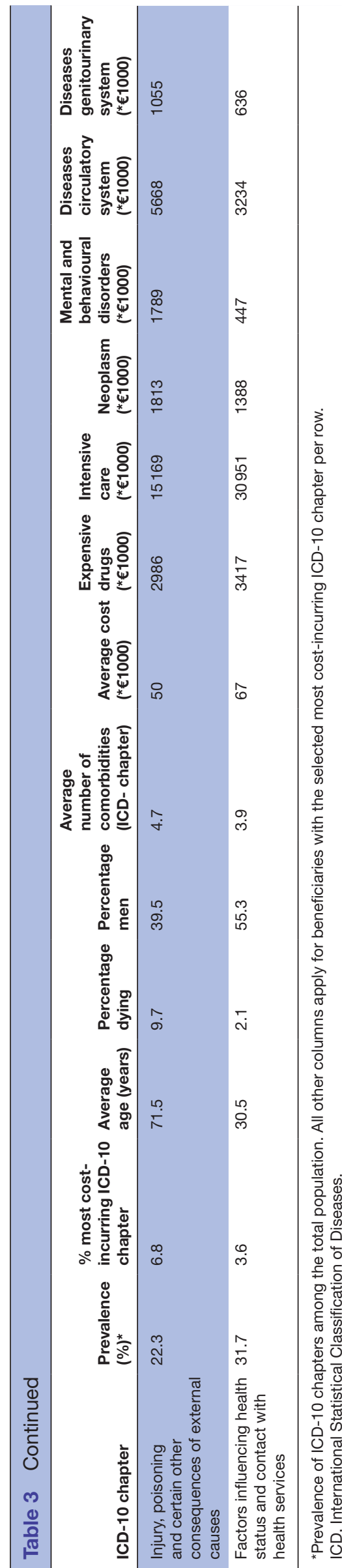

For each age group, there were different ICD-10 chapters with highest costs. Among top $1 \%$ beneficiaries, cardiovascular diseases and diseases of the genitourinary system gained importance with higher age, whereas mental and behavioural disorders predominated among younger and middle-aged beneficiaries. Among top $2 \%-5 \%$ beneficiaries, a similar pattern of diseases across age groups was observed. However, pregnancy-related conditions played a more significant role among beneficiaries between 20 and 40 years of age, and musculoskeletal conditions played a more significant role in several age groups than they did among top $1 \%$ beneficiaries.

\section{DISCUSSION}

In this study, we determined medical needs, demographics and utilisation patterns of high-cost beneficiaries in the Netherlands. Expensive treatments, most cost-incurring condition and age proved to be informative variables for studying this heterogeneous population. We found that expensive care use (expensive drugs, ICU treatment, dialysis, transplant care and DRG $>€ 30000)$ contributed to high costs in one third of top $1 \%$ beneficiaries and in less than $10 \%$ of top $2 \%-5 \%$ beneficiaries. High-cost beneficiaries were overwhelmingly treated for diseases of circulatory system, neoplasms and mental disorders. However, neoplasms and mental disorders were mainly found as most cost-incurring condition for a beneficiary, whereas circulatory disorders were mainly found as secondary condition. More than $50 \%$ of high-cost beneficiaries were 65 years of age or younger, and average costs decreased sharply with higher age within the top $1 \%$ population. Such insights are needed to develop tailored interventions and inform policy aimed at the high-need, high-cost populations.

\section{Strengths and limitations}

This was the first study assessing utilisation patterns of high-cost beneficiaries in a European universal health system, and we used innovative variables to examine characteristics and utilisation. We used data from one health insurer with a market share of approximately 27\%, with data representative for the Dutch population. Despite the limited number of variables, our data allowed detailed identification of healthcare use and categorisation of costs towards conditions. We chose to use expensive treatments, most cost-incurring condition and age as variables for further analyses as such analyses were lacking in the literature, and we regarded these as most informative for policy and practice. One limitation is that our analysis was restricted to 1 year only. Consequently, we could not discern persistent high-cost users from episodic high-cost users (those with single a high-cost event $t^{5}$ ).

\section{Reflections on our findings}

Our findings generally align with prior research on highcost beneficiaries. Similar to US studies, ${ }^{122}$ we identified three main subgroups of high-cost beneficiaries with 


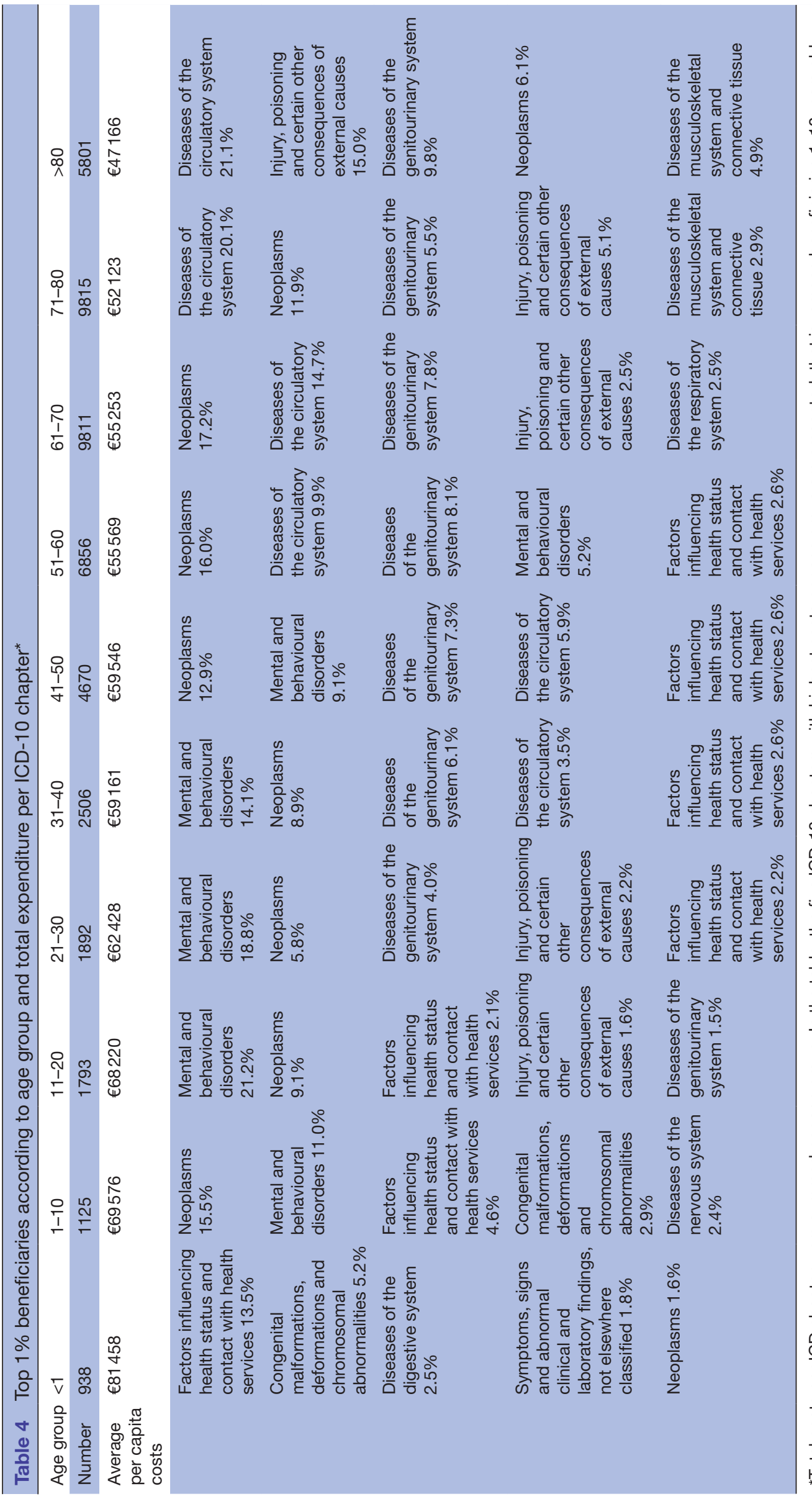

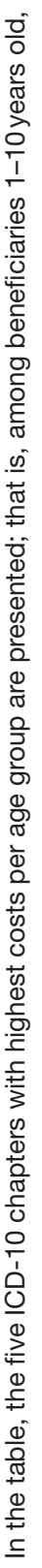

옹

흘

T.

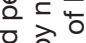

흔음

के

œ

3 造

这苋

웅

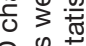

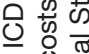

ळे 흥

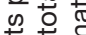

空

0

준 눈 
cardiovascular diseases, mental disorders and neoplasms, as well as several smaller subgroups. In addition, our findings confirm that high-cost beneficiaries are usually treated for several conditions and use care from multiple providers. ${ }^{10}$ Like prior studies, ${ }^{12}{ }^{22}$ we reported a high prevalence of diabetes, but this condition had a limited direct cost impact. This may be explained by the fact that Dutch diabetic care is primarily situated in primary care. Moreover, complications of diabetes were aggregated to the particular condition (eg, retinopathy) using our link table. Furthermore, in line with Aldridge and Kelley, ${ }^{5}$ we found that dying increases the risk for high costs (data not shown) but that less than $10 \%$ of high-cost beneficiaries were in their last year of life. However, we also found that $64 \%$ of those dying did not incur high costs, compared with $80 \%$ of decedents in the USA who did incur high costs. ${ }^{5}$ This may be explained by decedents that could have used long-term care services that were not included in our analyses. However, this may also result from the general practitioner-oriented organisation of palliative care in the Netherlands, which is known for its low costs. ${ }^{23} 24$

Our study is unique in estimating the relative contribution of expensive treatments in high-cost beneficiaries. The findings indicate that high unit costs for selected services play a substantial role in high-costs beneficiaries. We identified expensive treatment users among expensive patients. Furthermore, our analyses show expensive treatment users may use a lot of care besides such expensive treatments, suggesting that better alignment of expensive treatments with other care may be worthwhile. In line with Joynt $e t a l^{22}$, we suggest that expensive procedures (including orthopaedic surgery, pacemaker implantation and so on) and catastrophic events may be a more significant cost driver in high-cost beneficiaries than avoidable hospitalisations and that a complementary approach (see below) in high-need high-cost programmes is needed.

To our knowledge, we are the first that have distinguished the most cost-incurring versus secondary conditions in high-cost beneficiaries. For example, diseases of circulatory system were mainly found as a secondary condition, though they also frequently occurred as most cost-incurring condition. In addition, mental disorders and neoplasms were predominantly the most cost-incurring condition. Our findings contribute to the rapidly evolving field of multimorbidity and patterns of healthcare use. We suggest that conditions that were frequently and primarily found as most cost-incurring condition should be priorities for policies that seek to contain costs and improve quality of care. However, the observational nature of our study does not allow for causal inference; that is, the high number of morbidities in patients with cancer may either indicate the many complications from cancer treatment or point to prior chronic disease in patients with cancer.

Many high-cost beneficiaries were 65 years of age or younger; and the average costs decreased sharply with increasing age within the top $1 \%$ beneficiaries. In addition, we found typical care needs and utilisation per age group. Both findings have rarely been reported in literature ${ }^{10}$ and underline the need for studies in the general population with comprehensive data. Furthermore, high-need, high-cost programmes need to be aimed at beneficiaries of all ages; a mere focus on elderly would leave many high-cost beneficiaries unaddressed.

\section{Policy and research implications}

Our findings suggest a need for approaches that address patients' care needs across multiple conditions and to integrate care use across multiple providers. Important policy questions remain concerning the breadth of healthcare delivery innovations (ie, care coordination programmes, bundled payments and what should a bundle encompass?) ${ }^{25}$ We suggest that high-need, highcost programmes may aim to align the usual care for most cost-incurring conditions with the care for associated or common secondary conditions in specific care pathways. Furthermore, based on our findings, we recommend a complementary approach geared towards expensive procedures and drugs as well as the extensive additional care besides expensive treatments. This suggests bundled payments may be worthwhile, as well as multidisciplinary assessment of patients' care needs for expensive treatments. In addition, prices for expensive drugs or procedures could be lowered, for example, through reference pricing or competitive bidding. ${ }^{2627}$

Our research provides a precise picture of high-cost beneficiaries, but further research is necessary to specify characteristics and utilisation of high-cost beneficiaries at a local level. Patient segmentation analysis has been suggested as a method for identifying homogenous target population groups from diverse populations, which allows for tailored policies. ${ }^{28}$ Our analyses may inform such segmentation analyses. Furthermore, we suggest research into longitudinal patterns of multimorbidity to identify relevant subgroups that benefit from intervention. More research is needed to identify beneficiaries at risk of incurring high costs. ${ }^{29}$

In conclusion, our findings show that high-cost beneficiaries are usually treated for several conditions and use care from multiple providers. Expensive treatments, the most cost-incurring condition and age proved to be informative variables for studying this heterogeneous population. Tailored interventions are needed to meet the needs of high-cost beneficiaries and to avoid waste of scarce resources.

Acknowledgements The authors would like to thank Gerrit Hamstra for initial work in the study.

Contributors JJGW drafted the first manuscript and conducted the data analyses. JJGW, PVdW and MT conceptualised the study and interpreted the data. WJ provided assistance in data preparation, statistical analyses and was involved in interpretation of the findings. GPW and PPTJ made a substantial contribution to the development of the research question and interpretation and presentation of the findings. All authors provided feedback to and approved the final manuscript.

Funding The study was conducted as part of a research programme funded through the Dutch Ministry of Health. The funding source had no role in study 
design; in the collection, analysis and interpretation of data; in the writing of the report; or in the decision to submit the manuscript for publication.

Competing interests None declared.

Provenance and peer review Not commissioned; externally peer reviewed.

Data sharing statement No data are available.

Open Access This is an Open Access article distributed in accordance with the Creative Commons Attribution Non Commercial (CC BY-NC 4.0) license, which permits others to distribute, remix, adapt, build upon this work non-commercially, and license their derivative works on different terms, provided the original work is properly cited and the use is non-commercial. See: http://creativecommons.org/ licenses/by-nc/4.0/

C Article author(s) (or their employer(s) unless otherwise stated in the text of the article) 2017. All rights reserved. No commercial use is permitted unless otherwise expressly granted.

\section{REFERENCES}

1. Blumenthal D, Abrams MK. Tailoring Complex Care Management for High-Need, High-Cost Patients. JAMA 2016;316:1657.

2. Wennberg JE, Bronner K, Skinner JS, et al. Inpatient care intensity and patients' ratings of their hospital experiences. Health Aff 2009;28:103-12.

3. Bodenheimer T, Fernandez A. High and rising health care costs. Part 4: can costs be controlled while preserving quality? Ann Intern Med 2005;143:26-31.

4. Colla CH, Lewis VA, Kao LS, et al. Association between medicare accountable care organization implementation and spending among clinically vulnerable beneficiaries. JAMA Intern Med 2016;176:1167-75.

5. Aldridge MD, Kelley AS. The Myth Regarding the High Cost of Endof-Life Care. Am J Public Health 2015;105:2411-5.

6. Hayes SL, Salzberg CA, McCarthy D, et al. High-Need, HighCost Patients: Who are they and how do they use health care? A population-based comparison of demographics, health care use, and expenditures. Issue Brief 2016;26:1-14.

7. Hwang W, LaClair M, Camacho F, et al. Persistent high utilization in a privately insured population. Am J Manag Care 2015;21:309-16.

8. Zulman DM, Pal Chee C, Wagner TH, et al. Multimorbidity and healthcare utilisation among high-cost patients in the US Veterans Affairs Health Care System. BMJ Open 2015;5:e007771.

9. Lehnert T, Heider D, Leicht H, et al. Review: health care utilization and costs of elderly persons with multiple chronic conditions. Med Care Res Rev 2011;68:387-420.

10. Wodchis WP, Austin PC, Henry DA. A 3-year study of high-cost users of health care. CMAJ 2016;188:182-8.
11. Monheit AC. Persistence in health expenditures in the short run: prevalence and consequences. Med Care 2003;41:-53 64.

12. Riley GF. Long-term trends in the concentration of Medicare spending. Health Aff 2007;26:808-16.

13. Rosella LC, Fitzpatrick T, Wodchis WP, et al. High-cost health care users in Ontario, Canada: demographic, socio-economic, and health status characteristics. BMC Health Serv Res 2014;14:532.

14. Coughlin TA, Long SK. Health care spending and service use among high-cost Medicaid beneficiaries, 2002-2004. Inquiry 2010;46:405-17.

15. Kroneman M. The Netherlands: health system review. 18, 2016.

16. Mossialios E. Fund C, ed. International Profiles of Health Care Systems, 2015.

17. Smeets HM, de Wit NJ, Hoes AW. Routine health insurance data for scientific research: potential and limitations of the Agis Health Database. J Clin Epidemiol 2011;64:424-30.

18. WHO. International Statistical Classification of Diseases and Related Health Problems 10th Revision. 2016;23 http://apps.who.int/ classifications/icd10/browse/2016/en.

19. van Veen; SHCM. Evaluating and Improving the Predictive Performance of Risk Equalization Models in Health Insurance Markets. Erasmus University Rotterdam: Rotterdam, 2016.

20. NZa. Investigation of the accessibility and affordability of medicines in specialist medical care. Dutch: Dutch Healthcare Authority, 2015.

21. NZa. Open DIS data, 2016. www.opendisdata.nl.

22. Joynt KE, Gawande AA, Orav EJ, et al. Contribution of preventable acute care spending to total spending for high-cost Medicare patients. JAMA 2013;309:2572-8.

23. Evans N, Costantini M, Pasman HR, et al. End-of-life communication: a retrospective survey of representative general practitioner networks in four countries. J Pain Symptom Manage 2014;47:604-19.

24. Bekelman JE, Halpern SD, Blankart CR, et al. Comparison of Site of Death, Health Care Utilization, and Hospital Expenditures for Patients Dying With Cancer in 7 Developed Countries. JAMA 2016;315:272-83.

25. Herzlinger RE, Schleicher SM, Mullangi S. Health Care Delivery Innovations That Integrate Care? Yes!: But Integrating What? JAMA 2016;315:1109-10.

26. Acosta A, Ciapponi A, Aaserud M, et al. Pharmaceutical policies: effects of reference pricing, other pricing, and purchasing policies. Cochrane Database Syst Rev 2014;10:CD005979.

27. Stadhouders N, Koolman X, Tanke M, et al. Policy options to contain healthcare costs: a review and classification. Health Policy 2016;120:486-94.

28. Vuik SI, Mayer EK, Darzi A. Patient segmentation analysis offers significant benefits for integrated care and support. Health Aff 2016;35:769-75.

29. Vrijhoef B, Thorlby R. Developing care for a changing population: supporting patients with costly, complex needs. 2016 Nuffield Trust. 